\title{
Endangered Girls and Incendiary Objects: Unpacking the Discourse on Sexualization
}

\author{
R. Danielle Egan · Gail L. Hawkes
}

Published online: 23 October 2008

(C) Springer Science + Business Media, LLC 2008

\section{Erratum to: Sexuality \& Culture DOI 10.1007/s12119-008-9036-8}

The following errors were inadvertently overlooked:

The words "psychologic," "physiologic," and "historic" appear scattered throughout the article. The correct spelling is "psychological," "physiological," and "historical."

On p. 7, first paragraph, fourth line from bottom, change "corporation and media practice" to "corporate media practice."

On p. 8, delete the quotation marks at the beginning and end of the indented quote.

On p. 9, second paragraph from bottom, ninth line, remove the quotation mark in front of the word "childhood."

On p. 9, last line, change "childre" to "children."

On p. 11, second paragraph, fourth line, change "1890 s" to " 1890 s."

On p. 16, remove the quotation mark from the indented quote.

The online version of the original article can be found under doi:10.1007/s12119-008-9036-8.

R. D. Egan $(\bowtie)$

St. Lawrence University, Canton, NY, USA

e-mail: degan@stlawu.edu

G. L. Hawkes

University of New England, Armidale, NSW, Australia 